Cropley, M. \& Millward, L.J. (2009). How do individuals 'switch-off' from work during leisure? A qualitative description of the unwinding process in high and low ruminators. Leisure Studies, 28, 333-347.

\title{
How do individuals 'switch-off' from work during leisure? A qualitative description of the unwinding process in high and low ruminators
}

\begin{abstract}
There is growing interest in how workers recover and unwind from work during leisure, as poor unwinding has been associated with negative health. This research explores the recovery process to gain a greater understanding of how individuals switchoff from work related thoughts post work. Specifically, we conducted interviews with workers who habitually find it difficult to switch-off from work (i.e., high ruminators), and workers who find it easy to switch-off from work (i.e., low ruminators). Three master themes were elicited using Interpretative Phenomenological Analysis (IPA): (1) work philosophy, (2) coping strategies and (3) coping outcomes. The findings revealed differences in core beliefs about work; high ruminators perceive blurred boundaries between work and home life, and they allowed work to mentally predominate during their leisure time, whereas, low ruminators viewed their work and leisure as two distinct spheres, and actively developed strategies to switch-off and disengage from work. Both high and low ruminators acknowledged the health benefits of unwinding post work, yet only low ruminators managed to successfully do so. It was concluded that there is a need for organisations to educate their employees, particularly high ruminators, about the importance of strategic unwinding post-work to optimise the quality of leisure time and prevent them from becoming fatigued and burnt out.
\end{abstract}




\section{Introduction}

Unwinding from demanding work during leisure time is essential for optimal health and well-being. Failure to successfully unwind and switch-off from work has been associated with a number of health related problems. For example, sleep disturbance, is one common factor associated with poor unwinding (Akerstedt, Knutsson, Westerholm, Theorell, Alfredsson, \& Kecklund, 2002; Cropley, Dijk, \& Stanley, 2006; Nylen, Melin, \& Laflamme, 2007), and it has long been known that cognitive arousal prior to sleep, affects sleep quality (Gross \& Borkovec, 1982; Harvey, 2000). An inability to switch-off and stop thinking about work has also been associated with dysphoria and cardiovascular disease (Suadicani, Hein, \& Gyntelberg, 1993; Pravettoni, Cropley, Leotta, \& Bagnara, 2007). Switching-off from work is therefore an important means by which the demands of work can be prevented from creating long-term health problems.

A surprisingly high number of workers however find it difficult to unwind post work. For example, The Employment of Britain Survey (1992) interviewed over 3000 workers, $70 \%$ of whom found it difficult to unwind after work (Gallie, White, Cheng, \& Tomlinson, 1998). Various factors have been associated with poor unwinding. For instance, studies have shown that individuals reporting high demands and low control at work, ruminate more about work issues during their leisure time and take longer to unwind during the evening, compared to workers reporting low demands and high control at work (Cropley \& Millward Purvis, 2003; Cropley, et al, 2006). The teaching and the medical professions have been identified as being particularly demanding environments in which to work, and accordingly, studies have shown that a high proportion of workers in these types of occupations find it difficult to 'switch-off' post work (Aronsson, 
Svensson, \& Gustafsson, 2003; Cropley \& Millward Purvis, 2003; Gorter, 2005; Cropley et al., 2006). It is also known that the environment plays an important role and home workers find it particularly difficult to switch-off from work especially if they have to work in their every day living environment (i.e., kitchen, living room, bedroom), as they are continually reminded about their work (Dart, 2006).

What is less well understood is the actual process of unwinding. One line of research has investigated the activities people undertake post work as aids to unwinding (Sonnentag, 2001). However, it may not be the particular activity or task per se that people participate in during leisure time that aids unwinding; the important issue appears to be the underlying attributes of the experience of performing a particular activity (Sonnentag \& Fritz, 2007).

The most important, but the least well understood contributor to the unwinding process is variation in the relative ease by which people switch-off from work. Some people are able to switch-off easily, while others take a great deal longer (Cropley \& Millward Purvis, 2003). Unfortunately we know very little about switching-off processes and the mechanisms involved in unwinding. This paper aims to address this gap by exploring how workers 'switch-off' and unwind from work during their leisure time. We adopted a process-oriented qualitative approach and conducted interviews to examine the unwinding process from the perspective of the individual. By inviting participants to articulate their switching off experiences, the research process can capture them 'making sense' of these experiences. In so doing the researcher will necessarily assume a fundamentally interpretative role (e.g. Henwood \& Pidgeon, 1992). To this end we use an approach to qualitative psychology developed by Smith (1996; see 2004 for a review and 
reflection) called Interpretative Phenomenological Analysis (IPA). Interpretative Phenomenological Analysis was developed specifically for the investigation of how people make sense of their experiences and has three main epistemological roots: phenomenology (see Giorgi, 1995 for a review of phenomenological psychology), symbolic interactionism (see Denzin, 1995 for a review of how this particular epistemology informs qualitative psychology), and hermeneutics (Bernstein, 1983). The phenomenological root focuses IPA on individual lived experience. The symbolic interactionist root assumes that people make sense of their experiences and derive meaning from them through social interaction and dialogue. Finally, the hermeneutic root acknowledges the interpretative role of the researcher in 'making sense' of how an individual 'makes sense' of his or her lived experience (Smith, 2003, p. 51).

An IPA approach also involves a distinct configuration of methodological principles and recommendations for practice, namely idiographic, inductive, and interrogative. The idiographic principle gives primacy to subjectivity involving a detailed analysis of only a few individual accounts rather than aiming to describe objective reality outside of the lived experience. The inductive principle pertains to the way in which theory is evolved from the meanings derived from individual accounts as illustrated by Smith (1999). Finally the interrogative principle refers to the need for in-depth analytic inquiry (or "interpretative engagement") by the researcher who is co-constructing the meanings derived, as opposed to quantification and the formation of probability statements (Smith, 1999, p. 282). In order to develop a broad understanding of this process we conducted interviews with high and low ruminators. A high ruminator was identified as an individual who habitually finds it difficult to 
switch-off from work during their leisure time, and a low ruminator was considered as someone who finds it relatively easy to switch-off from work.

\section{Method}

Participants

Fifty participants were initially recruited by informal networking for the first screening phase of the study using an on-line survey comprising the Work-Related Rumination Scale (WRRS) (Cropley, \& Millward Purvis, 2003). The WRRS consists of 25 items, assessing how easily workers can switch-off from work (e.g., 'Do you become tense when you think about work-related issues during your free time; Do you leave work issues behind when you leave work?'). The response format utilized a five-point Likerttype scale $(1=$ very seldom or never, $2=$ seldom, $3=$ sometimes, $4=$ often, $5=$ very often or always). To overcome criticisms for the potential for snowballing samples to be biased in favour of researcher networks, a concerted effort was made to recruit from a wide variety of occupations and age demographics. The next stage sought to purposively select eight participants (four high ruminators, and four low ruminators') for IPA interviews. The distinction between high and low ruminators refers to how an individual experiences work-related thoughts once work is completed, and is not necessarily due to the type of work people are doing, or their grade. Nevertheless, in order to reduce the possibility of confounding rumination with occupational grade, workers were recruited from mid-level managerial posts, and were selected on the following grounds:

- Mid-level management across the public and private sector. 
- Predominantly office-based.

- Full-Time.

- 4 high scorers (upper $10^{\text {th }}$ percentile) and 4 low scorers (lower $10^{\text {th }}$ percentile) on the Work Related Rumination Scale.

Eight one-to-one interviews (age range 24 - 45 years, see Table 1) were conducted and this number is generally held to be sufficient to obtain rich, meaningful data for IPA analysis (Smith, 1996).

\section{INSERT TABLE 1 ABOUT HERE}

\section{Procedure}

Potential participants were contacted by either phone or e-mail to confirm their interest and suitability to take part, and were sent an information sheet containing details of the project, the interview procedure, and their rights as participants in advance of a possible depth interview (Smith \& Osborn, 2003). All consented to take part and for their interviews to be recorded. Before commencing the interview, its purpose, and the right to withdraw was reiterated. Participants reflected on how they coped with work-related issues and thoughts outside of work in semi-structured interview schedules lasting between 55 and 75 minutes. The schedule comprised 12 open-ended questions (pertaining to leisure activities, unwinding activities, the interface between work and non-work, work-related thoughts and their nature, and leaving work unfinished) to focus the conversation but mostly as a guide rather than a directive tool. This enabled participants 
to answer flexibly, elaborating on issues that they felt were appropriate, articulating their experiences with minimal involvement from the researcher. Participants were told that there are no right or wrong answers, and that the researcher was interested to hear about anything that the participant felt was important and most relevant to their 'switching-off' experiences.

\section{Analysis}

Eight verbatim interview transcriptions were analysed using Interpretative Phenomenological Analysis (IPA) guided by the technical advice of Smith and Osborn (2003), and Smith, Jarman, \& Osborn, (1999). Interpretative Phenomenological Analysis is essentially a phenomenological approach (Giorgi, 1995), concerning itself with how an individual makes sense of particular experiences, as opposed to attempting to objectively define and label these experiences (Smith et al., 1999). Yet, IPA recognises that direct access to a participant's life-world, and the meanings they hold for their experiences are not transparently available. Consequently, phenomenological analyses derived from the research process are interpretations of the participant's own interpreted experiences (Willig, 2001).

The analysis of transcripts followed an idiographic approach, beginning with the detailed analysis of a single case, and then moving on to examine the others, case by case, to slowly produce more general categories or claims (Smith et al., 1999). In this investigation, each 'case' consisted of an individual's account of his experiences allowing the researcher to capture higher-order psychological distinctions across the two sets of interviews for high and low ruminators respectively. This investigation commenced with 
a detailed analysis of one individual case by reading and re-reading the transcript numerous times to become familiar with their content, with initial notes and points of particular interest noted on the left hand side of the transcript. More theoretically-based and concise phrases were then generated that captured the essential quality of what was being said within the text. Connections between themes were listed on a separate sheet of paper in a table of themes (Smith et al., 1999), with cluster (super-ordinate) titles represented by the lower-order themes, along with verbatim examples of each and their location within the transcript (using line numbers). All other cases were similarly analysed.

This was followed by a cross-case analysis to identify common themes that were more or less representative of all cases (i.e., master themes) but which were also theoretically informative in terms of whether and if so, how they differentially played out across high or low ruminators (i.e., bipolar sub-themes). As IPA is an iterative process, it was important to continually revisit the text at every level of analysis, to ensure that the interpretations made were grounded in the participant's own words. As a result, care was taken when analysing other cases to recognise repeating patterns from previous accounts, but to also acknowledge new themes that were emerging. This would enable the researcher to recognise both the similarities and differences between the participants' accounts of the experience (Smith \& Osborn, 2003) without becoming detached from their original, idiographic origin. Themes derived from this final stage of analysis would represent the master themes, representing the phenomena under investigation in a condensed, abstract form using psychological content and theory (Millward, 2006). Of particular interest here was to identify higher order themes or constructs with 
implications for understanding critical psychological differences between high and low scoring ruminators.

\section{Results}

Three master themes were identified that were pertinent in differentiating the unwinding process between high and low ruminators: (1) work philosophy, (2) coping strategies and (3) coping outcomes. In accordance with Smith (1999) and other examples of published IPA research (see Millward, 2006), the results are presented with reference to benchmark 'high' and 'low' ruminator exemplars. These exemplars were chosen as they were agreed among the researchers to most typify each of the three master themes, and associated subthemes.

\section{Work Philosophy}

Participants justified their current work efforts in relation to three distinct work philosophies in relation to which high and low ruminators could be differentiated: live-towork/work-to-live, work over-commitment/detachment from work, and extrinsic/intrinsic motivation (Table 2).

INSERT TABLE 2 ABOUT HERE 
Live-to-Work or Work-to-Live

All high ruminators articulated a 'live-to-work' attitude whilst all low ruminators articulated a 'work-to-live' attitude. For example, Bill (high ruminator) asserted that:-

'I think work would win out, unless it is very, very important at home, I would have to do it'.

This emphasis put on the value of work by high ruminators can be contrasted with Peter's (low ruminator) comments,

...' even if I've got loads of stuff, I just get to the point in the day where I'm like right, I'm going home and I don't care, I'll just walk out, go home, and have a good weekend and then just get back on when I come back in...'

'everything's urgent but it's not that urgent, I kind of go with the philosophy that nothing's life-threateningly urgent, so um, it's yeah, there is pressure there, but I know I can sort of manage or tackle things as they come in and sort it out'.

Work Over-Commitment or Detachment from Work 
Work over-commitment, that is, working outside one's normal contractual hours, was evident across all high ruminator transcripts. Bill described how he regularly works "upwards of fifty five or sixty hours a week", but rather than see this as a lack of personal choice, his perception was that "long hours go with the territory". He added,

'Whether I work at home, work on the train, I don't think about it as being over time, it's just part of the job. I think my standard hours are between 35-40 hours a week'.

All high ruminating participants appeared in fact to have little knowledge or be slightly hazy as to their exact contractual hours, reflecting their tendency to simply work until a job is done. As Chris put it, 'it's pretty intense from where I go in, to when I leave'.

In contrast, the low ruminating participants were explicit about not working beyond their contractual hours. None of the low ruminators made any reference to a need to keep in touch with the office or work from home. In Peter's words,

'I think you can access your work email from home, but (laughs) but I never have. To be honest I don't actually think about work outside of work'

Similarly, Tony said, 
'I have a lap top which I take out and at home with me, it's wireless and connects to the server so I could work from home if I wanted to but I prefer not to'

Low ruminators also described a greater degree of autonomy than high ruminators in managing their working hours. Richard in particular, felt capable of managing his work in a self-governing fashion, adding to his sense of control over working hours and his ability to deal with problematic or stressful situations. Of his working hours, Richard said:

'I'm expected to do 36 hours each and every week but how I do the 36, is absolutely my own discretion, so I might have a long day of 10 hours and then a short day of 5 hours and if it all balances out, everyone is happy'

Extrinsic versus Intrinsic Motivation

High ruminators all tended to justify their work efforts with reference to external rewards. Reflecting on the importance of his work and his dedication, Bill (high ruminator) rationalised it as,

'it's just part of the job, it's the territory I'm in, I'm rewarded for that'

James likewise said, 
'I think what the difference is, at X, I am very well respected and the CEO knows I am doing a very good job, I've been given rewards, 3 separate rewards and recognition. So I know through these my superiors know I do a very good job'

In contrast, the low ruminators, particularly Richard referred to his motivation as intrinsic,

'I think I set my own standards and if I feel that I have done a decent day's work then I am happy'...'its not the fantastic salary, it's not the adulation, its personal professional pride. I work hard because I want to work hard, not because anyone makes me'.

\section{Coping Strategies}

This master theme pertains to strategies participants described using to cope with their work-related thoughts. The psychological and physical mediators of coping incorporated within this master theme also echo the extent to which the quality of participant's leisure time was enabled or hindered (see Table 3). The following coping strategies reflect differences between the high and low ruminators: blurred versus segregated boundaries, cognitive coping (repetitive or fleeting, intrusive or controlled), and social coping (withdrawal or social engagement). 


\title{
INSERT TABLE 3 ABOUT HERE
}

\section{Blurred versus Segregated Work-Home Boundaries}

\begin{abstract}
All high ruminators described how work monopolised their life which created a blurring of boundaries between work and home. For example, in discussing his use of technology to keep contact with the office, Bill said,
\end{abstract}

'I have a blackberry that I use all the time. I use it at home, I use it on the train, I use it on the golf course (laugh), I use it anyplace I have to, I use it on holiday'

High ruminators were especially susceptible to blurring across work and home life domains if they had tasks left unfinished or a deadline to meet. For example, Kelly said:

'If I haven't got as far as I want, then that will bug me and it will sit there in the back of my mind and frustrate me until I can get, get it sorted'...'I take work home with me mentally... but not in respect of actually to be able to do anything with it'

By contrast, all low ruminators were actively in control of their work and home boundaries, and consciously segregated them even when they had left tasks unfinished. 
All, for example, made reference to their journey into or away from work as some form of boundary marker. When discussing commuting to a previous job, Richard referred to his journey as follows:

'I worked in Redhill previously and I enjoyed that journey, I'd have my iPod in and I had an hour and a half each way but it was my time where I could shut the rest of the world'

Peter also described the way in which he physically detaches from work;

'I would say I'm pretty good at switching off and after I leave the office and err and getting home, I do tend to leave work at work'... 'I'm just one of those people that as soon as I've stepped out of the door, I just switch-off'

And Richard's approach to unfinished tasks was typical of the low ruminators:-

'I'm a great one for making lists at work of things I have to do and priorities... and if the list gets too long you pick a few of the quick ones and then generally the list gets shorter which psychologically is good but as long as you prioritise and get the minimum done then its not a problem'

Likewise Jessica said that she just had to 'accept that occasionally things would be left outstanding', but this would not result in 'any major impact'. 
Cognitive Coping - perserverative and intrusive thoughts versus cognitive control

All high ruminators described their work-related thoughts during leisure time as involuntary, repetitive, worrying, and above all, intrusive. It was the intrusive quality of perseverating thought that undermined the quality and enjoyment of their free-time. High ruminating participants described a variety of life-domains that were impacted upon, such as their sleep, social life, relaxation and exercise. Bill said,

'If it's really bad it can intrude onto everything. It can intrude on your social life, it can intrude on your sleep, it can intrude on your relaxation'

Bill also made the distinction between high or low pressure thoughts. In the citation above, he is describing high pressure thoughts. Bill found that his preoccupation with work-related thoughts made it hard for him to concentrate when socialising, to the point where he would prefer to be on his own to focus his thinking. His sleep was affected and he had on occasion resorted to finishing work during the early hours of the morning to sleep well.

'when you go to sleep you wake up. Eh, you know em, I've actually come down, logged on at 2 o'clock in the morning logged on to the server and did some work...but if you do that for an hour, then you could be quite tired. But if you solve the problem to a certain extent then you can remove the problem from your 
head. So the hour of lost sleep and work you've just done, often means you can go back up, eh and just turnoff and get to sleep. If you didn't do anything you could be lying there and the thought still running through your head'.

In contrast, active avoidance of intrusive thoughts was evident among the low ruminators. For them, work-related thoughts were only fleeting or triggered by an external source. Low ruminating participants in fact articulated a form of emotional detachment from work and even when cued to think about it, the thoughts were short, rational and nonrepetitive. As Tony said,

'If someone asks me what I am doing the next day, I tell them work wise, but that isn't grounds for me to think about anything outside the question'

Richard only thought and discussed work-related thoughts when socialising with people from work. Even in this situation Richard explained that he makes a conscious decision to steer the conversation away from work to limit the cues to activate work-related thoughts.

Tony and Richard described actively avoiding intrusive thoughts. Tony described removing himself from his desk at lunch and engaging with non-work related activities to stop intrusion into his relaxation time. He said, 'I guess that's the only active way I try not to think about work'. Richard discussed his preference towards participating in 
socialising rather than more passive tasks which allowed his mind to dwell on workrelated issues.

'I suppose if you're sitting at home and watching a DVD, unless it's particularly interesting, your thoughts could drift to jolly old work. But if you're out and about socialising, it's less likely to happen'

In contrast, to all the high ruminators, the low ruminating participants did not describe any problems relating to intrusive thoughts or disruptions to their leisure time.

Social Coping - Withdrawal versus Social Engagement

All of the high ruminators described withdrawal tendencies in response to work-related thoughts, which hindered socialising, and created feelings of isolation. Involuntary isolation would be due to the hindrance of work-related thoughts on socialising outside of work. As described by Kelly,

'I find I'm a bit sort of vacant and perhaps my husband can be talking to me for five minutes before I actually realise he's saying it, you know, I'm a bit sort of switched off and in my own world'

This form of fatigue and inability to concentrate on social interactions was alluded to by all the high ruminators. The low ruminators alternatively found that their social 
interactions were not impacted by work-related thoughts and when, on the occasions they did discuss problems pertaining to work, the interaction in itself appeared to assist their ability to unwind. Richard said,

'there probably have been times where yeah I probably was more likely to get in touch with mates and go for a drink in the evening, just to unwind, but that was only when I was going through a difficult phase with a certain individual'

Richard reported being close to his family and friends and seeks their assistance when needed. The low ruminators all referred to social networks affording them the opportunity to refocus their attentions from work-related thoughts to the present social interaction and conversation.

To summarise, high ruminators appear to be controlled by their work-related thoughts, undermining their ability to unwind and damaging the quality of their non-work life whereas low ruminators were able to control their work-related thoughts by segmenting work/non-work boundaries, detaching themselves cognitively, emotionally and also physically from work issues, and using their social life to optimise unwinding opportunities.

\section{Coping Outcomes}


This master theme (see Table 4) refers to differences between high and low ruminators in degree of cohesion or discord between work and non-work in relation to leisure (unfulfilled or fulfilled - cognitively resourceful/physically resourceful) and work-family (conflict or harmony).

\section{INSERT TABLT 4 ABOUT HERE}

\section{Leisure}

The high ruminators all described being unfulfilled by their leisure time, preferring to employ alternate forms of relaxation. For example, Bill said

'Sometimes I read, sometimes I do Sudoki, especially going in, in the morning it helps my brain get going, the best thing, we get free newspapers on the train in the morning, so give them a read and that's about it'

Bill in particular reiterated on numerous occasions that he was often fatigued during his leisure time and the long hours he worked often limited the amount he could participate in physical activities. The sports he wished to participate in, included tennis, golf and running; only occasionally did he managed to partake in golf at weekends. Other high ruminators also discussed wanting to participate in more physical sports like Chris, who 
described deriving enjoyment through participating in windsurfing and mountain biking, yet very infrequently did he have the chance to partake in these.

In contrast to the high ruminators, the low ruminators all described fulfilment and enjoyment of their choice of leisure activity. All reported engaging in some form of physical leisure. For example, Tony exercised during lunch breaks and evenings away from work,

'A typical evening for me, will be go home, get a little bit to eat, then go to the gym, or go straight there and get a little bit to eat after that'

Low ruminators actively sought physical exercise to enable them to 'switch off' and cognitively recuperate from the day.

Work-Home Conflict/Work-Home Harmony

Work-Home conflict was described by all the high ruminating participants. Bill described a conflict and a difficulty in balancing his work and home life because work appeared to monopolise his home life,

'there is always conflict, there...is the main things especially when you come to very busy periods and you do occasionally have to do 'all nighters' because you have to sign a company up, or when you get away on business, it can interfere' 
Bill, James and Kelly all described feeling guilty in relation to being absent from their families and children due to long working hours or when distracted by work-related issues. James also said that his nickname amongst friends was 'Larry Let Down' for constantly cancelling social engagements. Kelly also felt guilty because not only was she physically absent from her son whilst at work but also cognitively absent from him due to worrying about work, when she was at home.

The low ruminators seemed to describe a more cohesive and harmonious interaction between their home and work lives. As described by Jessica,

'If I wanted to do something in the evening it wouldn't stop us, like it we wanted to go to the cinema or out for a drink or something you know we would do it, it wouldn't stop us'

Richard also described a harmony between his work and home life and an ability to balance both. Once Richard arrived home he would watch television and after that he would feel completely unwound from work and able to enjoy his subsequent leisure time. Like other low ruminating participants, there appeared to be an understanding that work may consume more time than he would desire, however this was embraced and adapted to, rather than worried about or struggled with. As Richard put it, 
'I' $m$ in the fortunate position where I don't have the constraints of a family so when I need to work a bit later I can do and its, its not an imposition'

\section{Discussion}

The present study explored participants' experiences of unwinding from work relative to their high or low rumination tendencies. Three overarching themes emerged from the interviews: work philosophy, coping strategies and coping outcomes. A clear and consistent pattern emerged within all the themes, in that high and low ruminators appear to have different philosophy or mind set, about their work. For high ruminators, work was central to their identity and working hard and working long hours, was part of their core beliefs, and an accepted work culture. High ruminators do what is necessary in order to complete the job. In contrast, low ruminators consider work as a separate life experience and perceive their work and home life as two distinct worlds. This workleisure relationship appears to be consistent with the typology of work and leisure put forward by Parker (1983). For high ruminators there is not a clear demarcation between home and work, and work extends into leisure. In contrast, low ruminators see work and leisure as opposites, or aspects of two different neutral worlds.

It was interesting however, that even though the high ruminators appeared to accept the long working hours, reasoning that they were sufficiently rewarded for this imposition, they also reported that they were unable to escape from work. High ruminators also described the intrusiveness of work, and stated that ruminating about work impinged greatly on their leisure and monopolised their life (c.f., Pahl, 1995; 
Hochschild, 1997). This ultimately had a negative impact on health, as they reported a less active social life, compared to low ruminators, and ruminating about work prevented them relaxing.

Consistent with what has become to be known as the 'Zeigarnik effect', high ruminators also reported that if they left tasks incomplete, this would play on their mind, often resulting in frustration and repetitive rumination. Zeigarnik reported that unfinished/interrupted tasks are remembered better than completed ones (Zeigarnik, 1927). It is almost inevitable that some projects do not get completed and tasks will remain unfinished at the end of a working day or week, yet high ruminators were particularly prone to worry and ruminate about unfinished task once work related thoughts were triggered. By contrast, low ruminators were not troubled by leaving tasks uncompleted, and did not ruminate about unfinished projects during their leisure.

Another interesting finding was that low ruminators were able to switch-off from work relatively easily. This finding is consistent with a previous qualitative study exploring how surgical nurses manage their work stress. The nurses in this study used their ability to switch-off as a coping mechanism, and they also appeared to do this relatively easy, post work (Mackintosh, 2007). It was not clear however, whether the ability in nurses to switch-off, was related to the specific type of work they were doing, as they are able to 'pass things on to other people' at the end of their shift, and therefore be less inclined to think about work once their shift was over; or whether to some degree the ability to switch-off was related to age and experience. This raises the interesting issue of whether rumination changes overtime, and whether people can change from being a high ruminator to a low ruminator, or vice-versa? For example, a person could 
switch from being a high, to a low ruminator because of age, life stage or a change in work demands. Unfortunately, the stability of work-related rumination over time is not known. Evidence from the clinical field suggests however, that some individuals do demonstrate a general tendency to ruminate (Watkins, 2008), although studies tend to find only a modest test-retest reliability for rumination over time (Roelofs, Muris, Hulbers, Peeters \& Arntz, 2006; Hankin, 2008). Future research is needed to examine how static work-related rumination is over time, and also, if there are age differences in how people switch-off and unwind post work.

The concept of control at work has attracted a great deal of attention in the occupational health literature and control features in a core model of job stress (Karasek, \& Theorell, 1990). Control also appears to play a large part in the unwinding process, and control appears to be a distinguishing feature between high ruminators and low ruminators. Low ruminators feel in control of their work and leisure time, and low ruminators actively avoided thinking about work related issues when not at work. If a work related thought was triggered by an external source, low ruminators were able to deal with the thought in a non-judgemental way. Thus, low ruminators could remain emotionally detached from work, even if a work related thought was triggered. This was evidenced across difference aspects of leisure time activities and in one case an individual reported that he would actively steer a conversation away from work related issues when socialising.

The health benefits of exercising are well documented and both the high and low ruminators readily acknowledged the benefits and enjoyment in taking regular exercise. Here again there were differences, with the low ruminators using exercise in order to help 
them unwind and switch-off during their leisure time. A high ruminator by contrast reported that they had little time for exercise and if they did find time they had to limit the amount they did because they easily got tired.

Another noteworthy finding to emerge from the interviews concerns the use of technology. The emergence of portable computers and the advent of wireless equipment has made it easier than ever for workers to communicate with the office and to work remotely, and the natural physical boundary between work and home has become fragmented. It was a evident from the interviews however, that high and low ruminators use technology in different ways. Whereas high ruminators appear to be slaves to technology and will monitor emails during their leisure, even to the point of taking a Personal Digital Assistant (PDA) on holiday, low ruminators will not be tempted to connect to work during their leisure. Moreover low ruminators will use technology such as MP3 players in order to facilitate the unwinding process and help them unwind on the commute home.

As reported above, failing to adequately unwind and switch-off from work is associated with a number of negative health outcomes. With between $11-22 \%$ of workers describing themselves as regular worriers (Gallie, et al., 1998), it is important that interventions and guidelines are developed, to help those individuals, who report difficulty in switching-off from work, to unwind and recover from work demands in order to decrease the risk of workers becoming ill, fatigued or burnt out. Martin and Tesser, (1996) in their self-regulation model of ruminative thought offer three mechanisms to stop ruminative thinking: distraction, disengagement from the goal, and goal attainment. Goal attainment may be encouraged by training workers to break down 
projects into manageable chunks or tasks that can be completed on a daily basis, and it also may be possible to teach distraction techniques for workers to utilize in their leisure time. These could be cognitive (e.g., attention switching, thought stopping), or behavioural (e.g., playing sports or gardening). The process of unwinding however, appears multifaceted, and although this study revealed a number of potential areas interventions could be directed, e.g., the demarcation of home/work boundaries, restricting to use of technology away from work, the underlying goal being to increase workers sense of personal control both at work and during their leisure.

The present study is not without limitations and the ability to generalise from this study may be reduced because of the small sample and the findings may therefore not be representative of the population. The intention with IPA however, is not to build up a generalisable account of 'switching off' experiences but to produce a legitimate theoretical analysis from one specific sample, accountable both to participants (i.e. it feels true for them as a way of understanding their own personal experiences) as well as to external readers of the account (i.e., there is sufficient evidence provided from individual accounts to assure readers of our analytic credibility). Future work can then assess the empirical and theoretical generalisability of the analysis. Future research is also needed to disentangle the distinction between men and women in regards to unwinding from work, as women's experience of work and non-work time may be significantly distinct, when compared to the experience of men.

\section{Conclusion}


The overall finding from the interviews is that the process of unwinding and switchingoff from work during leisure is different for high and low ruminators. Whereas, low ruminators view their work and leisure as two distinct spheres, and actively strive to switch-off from work during their leisure time, high ruminators perceive less clear boundaries and work predominates much of their live. These results highlight the need for organisations to develop positive work-life balance initiatives for their employees in order to prevent them becoming fatigued and burnt out. 


\section{References}

Akerstedt, T., Knutsson, A., Westerholm, P., Theorell, T., Alfredsson, L. \& Kecklund, G.

(2002) Sleep disturbances, work stress and work hours: a cross-sectional study, Journal of Psychosomatic Research 53(3), pp. 741-748.

Aronsson, G., Svensson, L. \& Gustafsson, K. (2003) Unwinding, recuperation, and health among compulsory school and high school teachers in Sweden, International Journal of Stress Management 10(3), pp. 217-234.

Bernstein, R.N. (1983) Beyond objectivism and relativism: Science, Hermeneutics and Praxis (Philadelphia: University of Pennsylvania Press).

Cropley, M. \& Millward Purvis, L.J. (2003) Job Strain And Rumination About Work Issues During Leisure Time: A Diary Study, European Journal of Work and Organizational Psychology 12(3), pp.195-207.

Cropley, M., Dijk, D. J. \& Stanley, N. (2006) Job strain, work rumination, and sleep in school teachers, European Journal of Work and Organizational Psychology pp.15(2), 181-196.

Dart, J. (2006) Home-based work and leisure spaces: settee or work-station?, Leisure Studies 25, (3), pp. 313-328.

Denzin, N. (1995) Symbolic Interactionism, in: J.A.Smith, R. Harre, \& L.Van Langenhove (Eds) Rethinking Psychology, pp. 43-58 (London: Sage).

Gallie, D., White, M., Cheng, Y. \& Tomlinson, M. (1998) Restructuring the employment relationship (Oxford: Clarendon Press).

Giorgi, A. (1995) Phenomenological Psychology, in: J.A.Smith, R. Harre, \& L.Van Langenhove (Eds) Rethinking Psychology, pp. 24-42 (London: Sage) 
Gorter, R. C. (2005) Work stress and burnout among dental hygienists, International Journal of Dental Hygiene 3(2), pp. 88-92.

Gross, R.T. \& Borkovec, T.D. (1982) The effects of a cognitive intrusion manipulation on the sleep-onset latency of good sleepers, Behaviour Therapy 13, pp. 112-116.

Harvey, A.G. (2000) Pre-sleep cognitive activity: a comparison of sleep-onset insomniacs and good sleepers, British Journal of Clinical Psychology 39(3), pp. 275-286.

Henwood, K.L. \& Pidgeon, N.F. (1992) Qualitative research and Psychologial theorizing, British Journal of Psychology 83(1), pp. 97-111.

Hankin, B.L. (2008). Stability of cognitive vulnerabilities to depression: A short-term prospective multiwave study. Journal of Abnormal Psychology, 117(2), pp. 324-333.

Hochschild, A. (1997) The Time Bind (New York: Metropolitan).

Karasek, R.A. \& Theorell, T. (1990) Healthy Work (New York: Basic Books).

Mackintosh, C. (2007) Protecting the self: A descriptive qualitative exploration of how registered nurses cope with working in surgical areas, International Journal of Nursing Studies 44(6), pp. 982-990.

Millward, L.J. (2006) The transition to motherhood in an organizational context: An interpretative phenomenological analysis, Journal of Occupational and Organizational Psychology 7(3), pp. 315-333.

Nylen, L., Melin, B. \& Laflamme, L. (2007) Interference between work and outside-work demands relative to health: unwinding possibilities among full-time and part-time employees, International Journal of Behavioral Medicine 14(4), pp. 229-236.

Pahl, R. (1995) After Success (Cambridge: Polity).

Parker, S. (1983). Leisure and Work (London: Allen and Unwin). 
Pravettoni, G., Cropley, M., Leotta, S. N. \& Bagnara, S. (2007) The differential role of mental rumination among industrial and knowledge workers, Ergonomics 50(11), pp. 1931-1940.

Roelofs, J., Muris, P., Hulbers, M., Peeters, F. \& Arntz, A. (2006). On the measurement of rumination: A psychometric evaluation of the ruminative response scale and the rumination on sadness scale in undergraduates. Journal of Behavior Therapy and Experimental Psychiatry, 37(4), pp. 299-313.

Smith, J.A \& Osborn, M (2003) Interpretative phenomenological analysis, in: J.A. Smith (Ed) Qualitative Psychology: A Practical Guide to Methods pp. 51-80 (London: Sage).

Smith, J.A. (1996) Beyond the divide between cognition and discourse: Using interpretative phenomenological analysis in health psychology, Psychology and Health 11(2), pp. 261-271.

Smith, J.A. (1999) Identity Development during the transition to motherhood: an interpretative phenomenological analysis, Journal of Reproductive and Infant Psychology 17(3), pp. 281-299.

Smith, J.A. (2003) Validity and qualitative psychology, in: J.A. Smith (Ed) Qualitative Psychology: A Practical Guide to Methods pp. 232-235 (London: Sage).

Smith, J.A. (2004) Reflecting on the development of interpretative phenomenological analysis and its contribution to qualitative research in psychology, Qualitative Research in Psychology 1, pp. 39-54.

Smith, J.A., Jarman, M. \& Osborn, M. (1999) Doing interpretative phenomenological analysis, in: M. Murray and K. Chamberlain (Eds.), Qualitative health psychology: 
theories and methods pp. 218-240 (London: Sage).

Sonnentag, S. \& Fritz, C. (2007) The Recovery Experience Questionnaire: development and validation of a measure for assessing recuperation and unwinding from work, Journal of Occupational Health Psychology 12(3), pp. 204-221.

Sonnentag, S. (2001) Work, recovery activities, and individual well-being: a diary study, Journal of Occupational Health Psychology 6(3), pp. 196-210.

Suadicani, P., Hein, H. O. \& Gyntelberg, F. (1993) Are Social Inequalities As Associated with the Risk of Ischemic-Heart-Disease A Result of Psychosocial WorkingConditions, Atherosclerosis 101(2), pp. 165-175.

Watkins, E.R. (2008). Constructive and unconstructive repetitive thought. Psychological Bulletin, 134(2), pp. 163-206.

Willig, C. (2001) Beyond appearance: a critical realist approach to social constructionist work in psychology, in: D.Nightingale and J.Cromby (Eds.) Psychology and Social constructionism: a critical analysis of theory and practice pp. 37-52 (Buckingham: Open University Press).

Zeigarnik, B. (1927) Das Behalten erledigter und unerledigter Handlungen, Psychologische Forschung, 9, pp. 1-85. 